\title{
SHARED WRITING AS FIRST PHASE IN WRITING INSTRUCTION OF INTERMEDIATE PHASE AFRIKAANS HOME LANGUAGE LEARNERS
}

Maryna de Lange, Hanlie Dippenaar \& Johan Anker

Cape Peninsula University of Technology

Since 2012, the poor literacy levels of Intermediate Phase (IP) learners have been a concern for officials in the Western Cape Education Department (WCED). Responding to the literacy crisis, the WCED has implemented the South African Curriculum and Assessment Policy Statement (CAPS), along with various other literacy interventions, but in the West Coast District, IP learners' writing skills remain poor. Focusing on the West Coast District, this article sheds light on the implementation of writing-instruction practices in Afrikaans classrooms, specifically 'shared writing', as outlined in CAPS. The article maps the theoretical and conceptual framework of the writing process. In particular, it discusses Vygotsky's and Piaget's ideas on social-cognitive development and scaffolding, which propose that a competent adult should interactively model the writing process to learners before practice and independent writing are attempted. Current literature in the field of writing instruction foregrounds the concepts of 'thinking aloud' and a 'shared pen', according to which the teacher and learner co-compose a text, allowing teachers to model writing strategies and learners to become competent writers. In this study, quantitative and qualitative research methods were used to describe and understand West Coast District IP Afrikaans Home Language teachers' implementation of shared writing. Data collection consisted of quantitative and qualitative questionnaires, as well as interviews, with results converted into percentages. Subsequent data analysis disclosed the patterns, strengths and weaknesses experienced by IP Afrikaans Home Language teachers in the West Coast District, and provide valuable insights into the implementation of shared writing.

Key words: literacy, scaffolding; the writing process; shared writing; thinking aloud; shared pen

\section{INTRODUCTION}

Most South African learners are performing below the national curriculum's target of $50 \%$ and higher for literacy skills (Spaull, 2013: 7). Since 2009, the Western Cape Education Department (WCED) has introduced annual systemic literacy tests to determine the literacy levels of all Grade 6 learners in the province. Analysis of the results of Grade 6 Afrikaans Home Language (HL) learners between 2012 and 2014, as published by the WCED (South Africa, 2015), shows improvement in the literacy components of reading and viewing, thinking, reasoning and writing. However, WCED education officials are deeply concerned about the poor writing skills of learners in the Intermediate Phase (IP), as reflected by the systemic results. The WCED set a target of a $50 \%$ pass rate in the systemic tests, which was not achieved in the period from 2012 to 2014 (South Africa, 2015). The focus for this article is the writing component of the West Coast Education District (as illustrated in Table 1, second last row), where a pass rate of $20.1 \%$ for the period 2012-2014 was projected. 
Table 1: Results of the Grade 6 annual systemic test for literacy in Home Language, 2012 to 2014

\begin{tabular}{|l|l|c|c|c|}
\hline \multirow{2}{*}{ Literacy components of all Grade 6 learners as tested } & $\mathbf{2 0 1 2}$ & $\mathbf{2 0 1 3}$ & $\mathbf{2 0 1 4}$ \\
\cline { 3 - 5 } & Pass\% & Pass\% & Pass\% \\
\hline \multirow{2}{*}{ Reading and Viewing } & West Coast District & 42.1 & 22.3 & 41.9 \\
\cline { 2 - 5 } & Western Cape Province & 39.5 & 29.5 & 37.9 \\
\hline \multirow{2}{*}{ Thinking and Reasoning } & West Coast District & 41.8 & 19.4 & 38.8 \\
\cline { 2 - 5 } & Western Cape Province & 42.6 & 27.2 & 35.3 \\
\hline \multirow{2}{*}{ Writing } & West Coast District & $\mathbf{3 . 0}$ & $\mathbf{9 . 5}$ & $\mathbf{4 7 . 8}$ \\
\cline { 2 - 5 } & Western Cape Province & $\mathbf{5 . 1}$ & $\mathbf{1 9 . 3}$ & $\mathbf{3 0 . 9}$ \\
\hline
\end{tabular}

Adapted from South Africa (2015)

Despite various literacy interventions introduced by the South African Department of Basic Education (2012 Curriculum and Assessment Policy Statement and national workbooks), by the WCED (a literacy intervention facilitated by the non-government organisation READ Educational Trust), and on the district level (the monitoring of daily writing), the required pass rate of 50\% in writing could not be reached. It might be the case that the reasons for the poor performance were not addressed by these interventions. The current South African curriculum, Curriculum and Assessment Policy Statement (CAPS), includes shared writing as the first stage of scaffolding in the process of writing, where 'each lesson should be one that engages the whole class before practising in groups and applying the new skill individually' (South Africa, 2011: 13). As outlined in CAPS, shared writing refers to demonstrating, talking through and showing how as a whole class activity; it is a way to construct a text through teacher-led interaction (South Africa, 2011: 13).

The aim of the present research was to determine how effectively Afrikaans IP teachers follow the CAPS guidelines and implement shared writing in their classrooms. The study set out to answer the following research question: To what extent do teachers in Afrikaans HL classrooms in the West Coast Education District use shared writing to teach the writing process to IP learners? (South Africa, 2011: 13). The study also focused on the scaffolding methods used by teachers to improve literacy results (Van der Veer, 2007: 118).

\section{THEORETICAL FRAMEWORK}

The theory in which this research is grounded is that of social cognitive constructivism. Piaget's work on cognitive development and learners' interaction with the environment, and Vygotsky's work on social development are the main theories on which social cognitive constructivism relies. Both Piaget and Vygotsky place emphasis on active learner participation during the construction of knowledge. Piaget proclaims that learners take responsibility for their own learning, while Vygotsky states that social interaction between teacher and learners is essential for constructing new knowledge via scaffolding (Piaget, 1977: 70; Vygotsky, 1978: 123). The construction of knowledge is based on the support given to a learner through social interaction and self-discovery, with the teacher playing the role of a facilitator. Learners observe, explore and take responsibility for learning by interacting with the rest of the class (Doubleday et al., 2015: 44). 
Vygotsky recognises that the social origins of knowledge construction lie in communicating with others. He states that social interaction plays a fundamental role in the development of understanding: first between people (inter-psychological), and then inside the child (intrapsychological) (Vygotsky 1978: 57). The following four stages in the scaffolding of writing are described as:

- Stage 1: Modelling expectations for writing (explaining, demonstrating, question probing, reflecting) to learners through verbal interaction, while demonstrating how to construct a text.

- Stage 2: Explaining the task and the skills needed to complete it successfully.

- Stage 3: Allowing learners to practise the writing skills as modelled.

- Stage 4: Ensuring that learners have internalised the skills and can work independently.

Therefore, modelling (stage 1) is considered the starting point that leads to independence. In this paper, the modelling of writing is referred to as 'shared writing', which is the terminology used in CAPS (South Africa, 2011: 13). Shared writing can be explained as the method by which the teacher demonstrates or models writing to learners. This method includes talking through, instructing, writing as a whole class, and teacher-led interaction, which allows learners to 'discover' the writing process for themselves (Fischer, 2002: 65; Galbraith, Ford, Walker \& Ford, 2005: 118). During shared writing, the teacher models the different phases of the writing process (such as planning, drafting and editing) by involving the whole class (Bower, 2011: 24; Laycock, 1991: 18). The aim of the shared writing component is to free learners' working memory and allow them to concentrate on the thinking processes involved in mastering a particular writing skill (Milian, 2005: 335, 337; Pearson \& Gallagher, 1983: 325). Button, Mathieu and Zajac (1996: 446), and Brandt (1998: 1) argue that interactive writing refers to teachers' engagement in effective writing instruction, which is complemented by learners' contributions regarding the personal and collective meaning of the entire writing process. Talking through the writing process is an effective way of scaffolding learners in the process of writing, providing support to those who experience barriers or lack confidence or motivation (Te Kete Ipurangi, 2015: 1). Wall (2008: 149) states that, through shared writing, learners can 'experience' thought processes interactively, and can be guided in the appropriateness, functionality and procedures commonly used by experts from the planning stage all the way to the publication stage.

Shared writing can be further explained using two methods of capturing learners' attention and involving them interactively: namely, 'thinking aloud' and 'shared pen' (Diagram 1). 'Thinking aloud' refers to sharing one's thoughts, or 'verbal thinking', on the part of an adult (Van der Veer, 2007: 80). As a team, the teacher and learners brainstorm ideas and decide on the best order in which to present them (Eggleton, 2010: 90; South Africa, 2011: 11; Tann, 1991:186). Learners are given an example and encouraged to follow the demonstrated thinking process they have been exposed to. 'Shared pen' involves the learners informing the teacher what to write on their behalf, as illustrated in Figure 1 (Paquette, 2007: 163). This focused verbal interaction can be beneficial in imparting knowledge and accommodating different learning styles during writing instruction (Barringer et al., 2010: 49). 


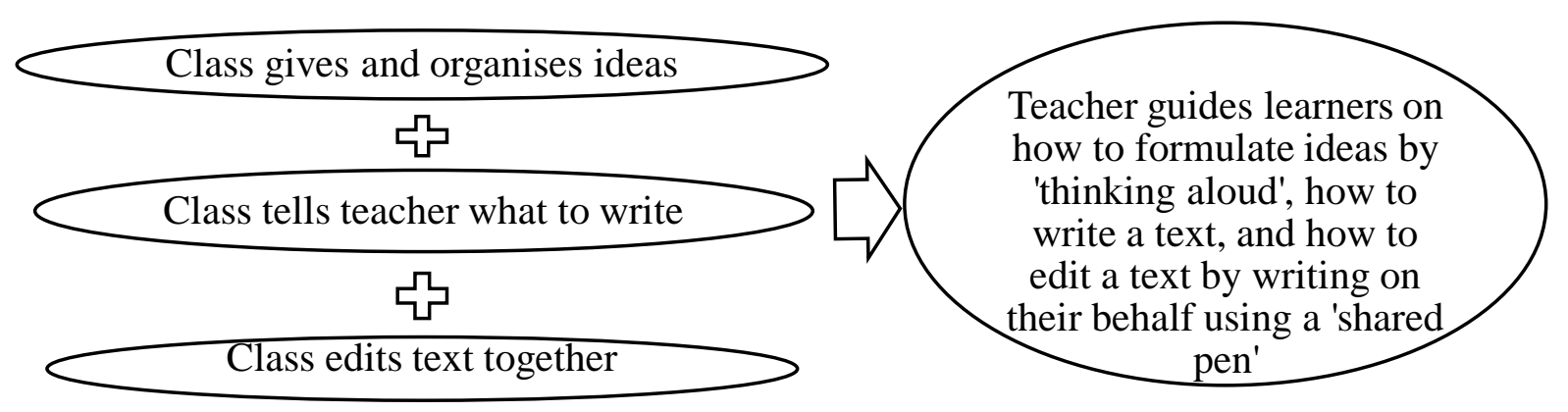

Figure 1: Shared writing in relation to 'thinking aloud' and 'shared pen'

When learners master the process, the brain allows working memory to operate spontaneously, inspiring learners to be creative (Galbraith et al., 2005: 118). This instructional approach is thought to create the ideal conditions for learning (Brandt, 1998: 1). The writing process is broken down into manageable chunks of information, in an attempt to free the learner's working memory and store information in long-term memory (Gagne \& Driscoll, 1988:12; Fischer, 2002: 65). This method could be an effective way of visually creating (through Vygotsky's mediated memory) an example of the required written task, and thus of supporting successful writing (Lan et al., 2011: 151). For the benefit of learners' writing abilities, teachers need to be informed of this instructional approach. These arguments form the basis of the scaffolding approach outlined in CAPS, and the majority of WCED teachers have been trained in the shared writing methodology (South Africa, 2011: 13).

\section{METHODOLOGY}

In order to determine whether scaffolding, in the form of shared writing, is implemented effectively in IP Afrikaans HL classes in the West Coast District, this study required a reliable research design. The researcher selected an interpretivist paradigm, and included both quantitative and qualitative research design methods as a way to gain different perspectives on the research problem and ensure trustworthiness (Creswell \& Clark, 2011: 104). In order to meet the aims of the study, the research methods were applied in two phases: quantitative and qualitative data collection, and the quantitative comparison of data. The research design process can be subdivided into the following components, described in detail below: participants, ethical considerations, instrument, data collection and data analysis.

\section{Participants}

The sampling of participants was done differently for the quantitative and qualitative research methods. The quantitative research sampling process was twofold. The annual literacy systemic diagnostic quantitative testing (data set 1) assesses the level of writing skills among Grade 6 learners in the West Coast District, producing the 2012-2014 systemic testing results for literacy (Table 1). A sample of 82 IP Afrikaans HL teachers, selected from a pool of 160 IP Afrikaans HL teachers in the West Coast District, was used as a non-probability sample for data set 2. Non-probability sampling was dependent on school principals, who distributed the questionnaires to their teachers, with each participant having an equal opportunity to be selected. From this sampling method, generalisations were made about the larger population. 
The qualitative sampling process (open-ended questionnaires) was threefold. The population was purposively sampled to provide the researcher with an in-depth understanding of how and to what extent IP Afrikaans HL teachers implement shared writing and teach the writing process according to the requirements of CAPS (Creswell, 2009: 181). Schools that underperformed in the WCED systemic tests, and that had been exposed to training by the NGO READ Educational Trust, were identified. 25 IP Afrikaans HL teachers from these schools in the West Coast District completed an open-ended questionnaire, and nine interviews were conducted with the same group of IP Afrikaans HL teachers, in line with Creswell's (2008: 153) recommendations. Finally, READ facilitators were requested to share their views on IP Afrikaans HL teachers' implementation of shared writing. The results of 82 quantitative questionnaires, 25 qualitative questionnaires, nine interviews, and two outsiders' perspectives were collected, allowing for triangulation (see Table 3). This triangulated approach afforded the researcher rich insight into the phenomenon being investigated.

\section{Ethical considerations}

Koonin (2014: 263) states that researchers should have the support and trust of broader communities, such as the participants, the public, other researchers, the faculty and policymakers. Ethical clearance was provided by both Cape Peninsula University of Technology and the WCED. Before the study was conducted, consent letters were issued to all participants, informing them formally of the purpose of the research, the instruments being used, the duration of the research, the date of research, the venue of the research, and how their identities would be protected. The consent forms stipulated that information would be known only to the researcher, and would not be made available to any other person (Creswell, 2008: 238; Louw, 2014: 264). The consent form also highlighted the fact that participation was voluntary, and that the research could potentially benefit participants' teaching and have a positive impact on education (Basit, 2010: 93). Participants had to sign an acknowledgement that they had given consent for their contribution to be used in the study (Koonin, 2014: 267). The contact details of the Ethics Council, the supervisor and the researcher were made available to all participants.

\section{Instruments}

To address the aims of the research study, the researcher gathered data using five separate instruments, of which two were quantitative (data sets 1 and 2) and three were qualitative (data sets 3 to 5). The findings of the two separate research designs were compared, as illustrated in Figure 2. 


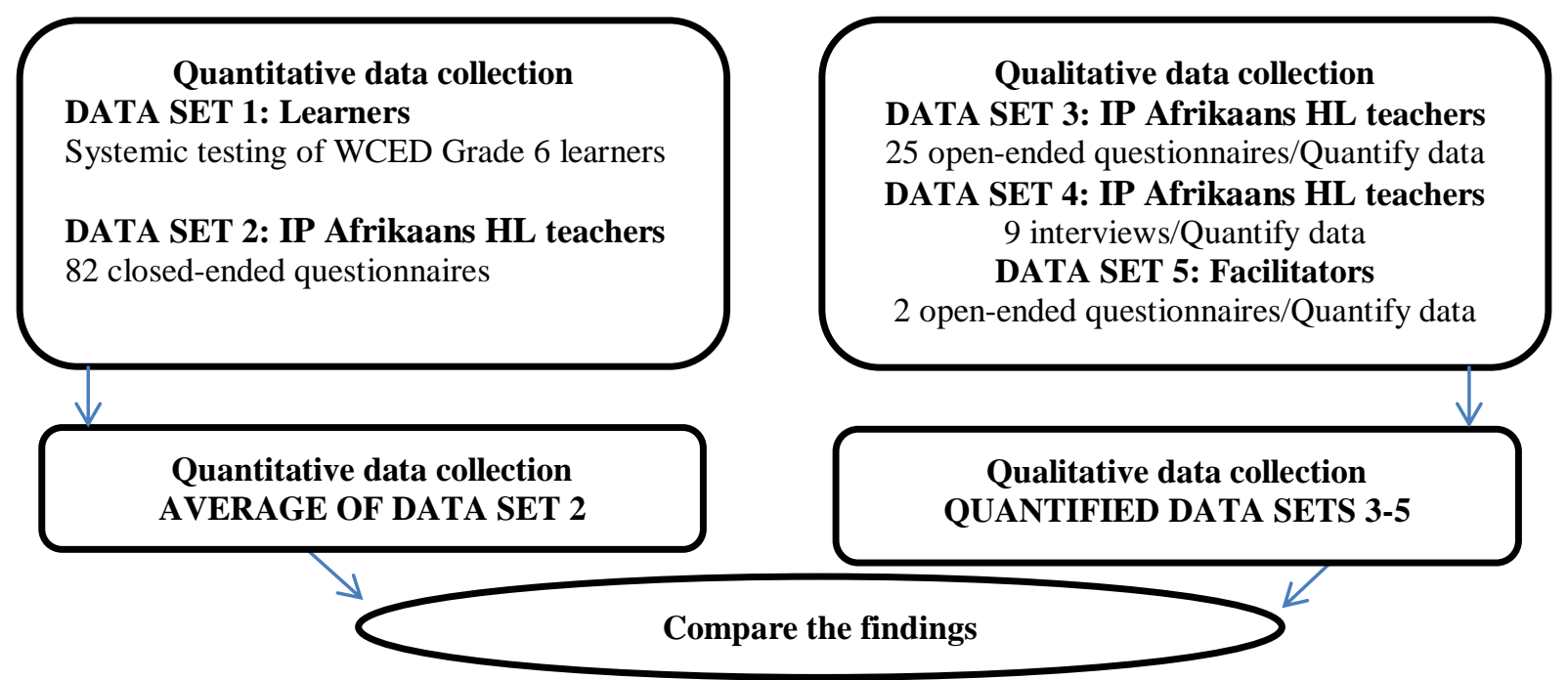

Figure 2: The quantitative and qualitative research methods

Based on Creswell and Clark (2011: 118)

The first quantitative data set (data set 1) included the WCED quantitative systemic testing results for literacy for the period 2012-2014, which could indicate a problem in the way writing is taught in the West Coast District and in the Western Cape at large (see Table 1). To investigate this problem, a cross-sectional survey, data set 2 (closed-ended questionnaires), was used to determine IP Afrikaans HL teachers' general perspective of their own teaching practices (Fink, 2002: 102) and of their implementation of CAPS (Table 2).

Table 2: CAPS shared writing requirements, against which data were compared

\begin{tabular}{|c|c|}
\hline $\begin{array}{l}\text { Categories of } \\
\text { shared writing }\end{array}$ & $\begin{array}{l}\text { Statements expected of teachers, according to the CAPS shared writing } \\
\text { requirements }\end{array}$ \\
\hline $\begin{array}{l}\text { Planning } \\
\text { phase }\end{array}$ & $\begin{array}{l}\text { - Discuss the purpose and audience of a text with learners. } \\
\text { - Model to learners how to consult resources and brainstorm ideas. } \\
\text { - Model to learners how to select relevant information for the purpose and } \\
\text { audience. } \\
\text { Model to learners how to sort and organise ideas into the format of the text } \\
\text { type. }\end{array}$ \\
\hline $\begin{array}{l}\text { Drafting } \\
\text { phase }\end{array}$ & $\begin{array}{l}\text { - Model to learners how to produce a first draft that takes into account the } \\
\text { - } \text { Morpose, audience, topic and text structure. } \\
\text { - Model to learners how to write the beginning of the text from the planning. } \\
\text { - Model to learners how to write the middle of the text from the planning. } \\
\text { - Me the the }\end{array}$ \\
\hline $\begin{array}{l}\text { Editing } \\
\text { phase }\end{array}$ & $\begin{array}{l}\text { - } \quad \text { Learners read drafts critically and get feedback from others. } \\
\text { - Model to learners how to edit a draft. } \\
\text { - } \quad \text { Model to learners how to identify mistakes and correct sentences of a draft. } \\
\text { - } \quad \text { Expect learners to produce a neat, legible, edited final version. }\end{array}$ \\
\hline
\end{tabular}
Adapted from South Africa $(2011: 12,13)$

The closed-ended questionnaire was designed by formulating three categories, each with four descriptions in the form of statements. The statements were conceived using the expectations outlined in CAPS. A Likert scale was used to indicate the extent to which participants agreed or disagreed with each statement (Du Plooy-Cilliers \& Cronje, 2014: 159). 
The qualitative design instruments (data sets 3, 4, and 5) included descriptive questionnaires with open-ended questions and interviews. Data set 3 consisted of open-ended questionnaires in which teachers described their practices. These questionnaires were followed by recorded interviews (data set 4) where teachers could explain their practices verbally. Lastly, in data set 5 , READ facilitators completed open-ended questionnaires to provide their views of how teachers implement shared writing and teach the writing process in IP Afrikaans HL classrooms.

The rationale for collecting both quantitative and qualitative data was to gain exploratory and explanatory perspectives on the phenomenon being studied (Davis, 2014: 75, 77). Disparate data collection instruments were used to gather in-depth knowledge on how shared writing and the writing process are implemented in the IP Afrikaans HL classroom on the one hand, and on how teachers perceive their own teaching practices on the other, with teachers' perceptions assessed through their responses to the quantitative questionnaires (Fink, 2002: 114).

\section{Data collection procedures}

The data collection procedure occurred in three phases: phase 1 covered the administration necessary for the research study; phase 2 covered the execution of the quantitative research design; and phase 3 covered the execution of the qualitative research design.

During phase 1, the WCED systemic results for literacy for the 2012-2014 period were analysed, which indicated a concern regarding the writing component (South Africa, 2015). Basit (2010: 317) suggests that permission be obtained for any research conducted within a social context. Ethical clearance was acquired from the CPUT Faculty of Education and from the WCED, after which consent letters were issued to the READ Educational Trust, and to principals and teachers.

Phase 2 of the research involved quantitative closed-ended questionnaires being distributed to principals at 50 different schools and offered to the IP Afrikaans HL teachers at those schools (Table 3).

During phase 3 of the research, the qualitative questionnaire (with open-ended questions) was emailed to eight schools. Teachers from four of the eight schools were then invited for interviews once they had completed the questionnaire, to provide more detailed information on the same questions (Table 3). Finally, the researcher emailed qualitative questionnaires to a number of READ facilitators, gathering written descriptions of their observations of how shared writing is implemented in IP Afrikaans HL classrooms in the West Coast District (Table 3). The results of phases 2 and 3 were merged and interpreted. From these different perspectives, similarities, differences and gaps were identified and discussed (Creswell, 2009: 114). 
Table 3: Summary of number of circuits, schools, participants, and instruments used

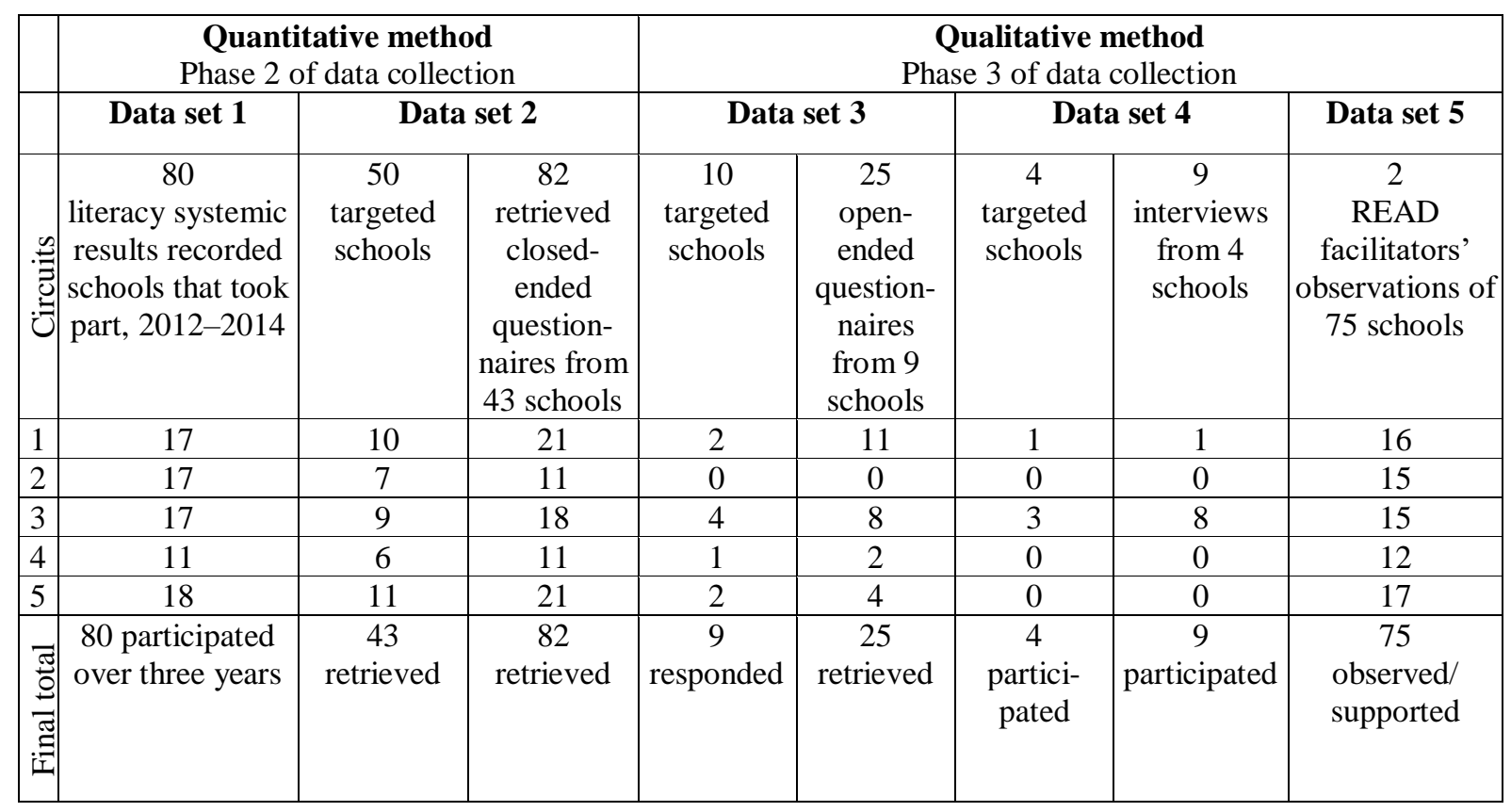

\section{Data analysis}

To ensure the validity of the research instruments, it was crucial to accurately capture and analyse the data. As Creswell (2009: 246) proposes, quantitative and qualitative categories need to be similar if the researcher wants to produce accurate findings through triangulation.

The quantitative phase consisted of two data sets. Data set 1 consisted of the results of the Grade 6 learners' systemic testing (as published by the Western Cape Education Department in 2015) and indicated poor writing skills among learners. Data set 2 consisted of a closed-ended questionnaire and was offered to 82 IP HL teachers throughout the West Coast District. Khan (2014: 209) emphasises the importance of accuracy and precision. The researcher used ordinal and nominal scales for the biographical data. The results of a one-way ANOVA test show that there is no significant difference in biographical factors such as gender (T-value $=0.306$, d.f. $=$ 81 , $\mathrm{p}$-value $=0.761)$, exposure to the READ programme $(\mathrm{T}$-value $=0.548$, d.f. $=79, \mathrm{p}$-value $=$ $0.585)$, teaching experience $\left(\mathrm{F}_{2 ; 80}\right.$-value $=0.625$, p-value $\left.=0.538\right)$, and qualifications $\left(\mathrm{F}_{2 ; 80^{-}}\right.$ value $=1.12, \mathrm{p}$-value $=0.332$ ). Likert scales were used to determine the implementation of CAPS (Table 2), with the results recorded in Microsoft Excel using pivot tables and analysed by the CPUT Statistical Consultation Centre using SPSS 23 (Bezuidenhout \& Cronje, 2014: 229; Frankel \& Wallen, 2006: 463). The findings were displayed numerically and statistically, as in Table 3 (Creswell, 2009: 350; Fink, 2002: 32).

The CAPS rubric contains four descriptives, and a maximum of four correlations could therefore be made in each category, as shown in Table 2 (Driscoll, Appi ah-Yeboah \& Douglas, 2007:25). The qualitative data (open-ended questionnaires, interviews and the written descriptions of the READ facilitators) were quantified and coded according to set categories, as per the examples provided in Table 4 (planning), Table 5 (drafting), and Table 6 (editing). 
Table 4: Data set 3: examples of quantifying qualitative data (done for 25 teachers): open-ended questionnaires on shared writing: planning

\begin{tabular}{|c|l|c|c|}
\hline Participant & $\begin{array}{l}\text { Teacher's description } \\
\text { Quantification: Any word that indicated } \\
\text { teacher involvement or modelling was shaded } \\
\text { and coded (South Africa, 2011: 11-13) }\end{array}$ & $\begin{array}{l}\text { Code } \\
\text { awarded }\end{array}$ & $\begin{array}{l}\text { CAPS: Writing process } \\
\text { planning requirements, as set } \\
\text { out in Table 2 }\end{array}$ \\
\hline 11 & $\begin{array}{l}\text { 'Point at a template' } \\
\text { 'I write the planning on the board. They must } \\
\text { add main ideas on their own' }\end{array}$ & $\begin{array}{l}\text { 'Bring example of text to school. Read it to } \\
\text { learners and plan a story' }\end{array}$ & 2 \\
\hline 12 & $\begin{array}{l}\text { Discuss purpose and } \\
\text { audience } \\
\text { Model how to consult } \\
\text { resources, brainstorm ideas } \\
\text { Select relevant information } \\
\text { Sort and organise ideas }\end{array}$ \\
\hline
\end{tabular}

Table 5: Data set 3: examples of quantifying qualitative data (done for 25 teachers): open-ended questionnaires on shared writing: drafting

\begin{tabular}{|c|c|c|c|}
\hline Participant & $\begin{array}{l}\text { Teacher's description } \\
\text { Quantification: Any word that indicated } \\
\text { teacher involvement or modelling was shaded } \\
\text { and coded (South Africa, 2011: 11-13) }\end{array}$ & $\begin{array}{l}\text { Code } \\
\text { awarded }\end{array}$ & $\begin{array}{l}\text { CAPS: Writing process } \\
\text { drafting requirements, as set } \\
\text { out in Table } 2\end{array}$ \\
\hline 8 & 'Give an example - discuss' & 1 & \multirow{3}{*}{ 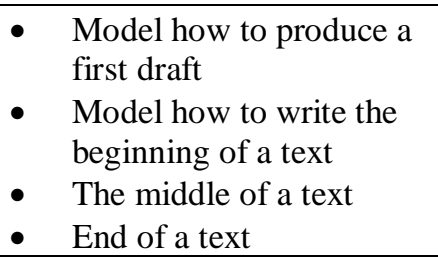 } \\
\hline 20 & $\begin{array}{l}\text { 'Do planning first. Start each paragraph } \\
\text { individually' }\end{array}$ & 0 & \\
\hline 23 & 'Write format correctly on board' & 0 & \\
\hline
\end{tabular}

Table 6: Data set 3: examples of quantifying qualitative data (done for 25 teachers): open-ended questionnaires on shared writing: editing

\begin{tabular}{|c|l|c|c|}
\hline Participant & $\begin{array}{l}\text { Teacher's description } \\
\text { Quantification: Any word that indicated } \\
\text { teacher involvement or modelling was shaded } \\
\text { and coded (South Africa, 2011: 11-13). }\end{array}$ & $\begin{array}{l}\text { Code } \\
\text { awarded }\end{array}$ & $\begin{array}{l}\text { CAPS: Writing process editing } \\
\text { requirements, as set out in } \\
\text { Table 2 }\end{array}$ \\
\hline 6 & $\begin{array}{l}\text { 'Learners do not have the ability to correct } \\
\text { mistakes' }\end{array}$ & 0 & $\begin{array}{l}\text { - } \\
\text { Read critically, get feedback } \\
\text { Model how to edit a draft }\end{array}$ \\
\hline 4 & $\begin{array}{l}\text { 'Let peers edit each other's work' } \\
\text { 'Learners know how to edit a text, but tell them } \\
\text { every time to edit and to remember and to } \\
\text { make sure that the format and text is correct' }\end{array}$ & 1 & $\begin{array}{l}\text { Identrect sentences } \\
\text { Expect a neat legible, edited } \\
\text { final version }\end{array}$ \\
\hline
\end{tabular}

Data sets 2-5 were calculated (producing averages of the awarded codes), represented in percentages, and compared to the systemic results (data set 1 ) over three years. This step was intended to determine whether it is possible to identify the lack of implementation of shared writing as a possible reason for the poor results. The two sets of data could then be compared to determine the extent to which teachers implement shared writing while teaching the writing process.

\section{COMPARISON OF QUANTITATIVE AND QUALITATIVE DATA SETS}

Triangulation was used to determine whether (data set 2) and how (data set 3 to 5) teachers implement the CAPS content and the shared writing approach in the West Coast Education District, as a way to explain the systemic results of 2015. The different instruments produced different results. Table 7 compares the quantitative (data set 2) and qualitative (data sets 3, 4 
and 5) average implementation percentages to data set 1 . The systemic results (data set 1) identified the problem, as seen in the last row of Table 1 (20.1\% average pass rate over three years). The quantitative questionnaires (data set 2), meanwhile, revealed that 82 teachers implemented shared writing's planning, drafting and editing phases with percentages higher than $67 \%$. The qualitative data, open-ended questionnaires (data sets 3 and 5) and interviews (data set 4) were also quantified, revealing that teachers' implementation percentages for shared writing (planning, drafting, and editing) were in fact lower than $67 \%$, as shown in Table 7.

Table 7: Comparison of quantitative and qualitative data using average implementation percentages per data set of the CAPS shared writing approach

\begin{tabular}{|c|l|c|c|c|}
\hline Data sets & \multicolumn{1}{c|}{ Questionnaires } & \multicolumn{3}{c|}{ Average percentage of writing categories } \\
\hline 1 & $\begin{array}{l}\text { Grade 6 learners systemic } \\
\text { writing results }\end{array}$ & \multicolumn{3}{c|}{20} \\
\hline & & Planning & Drafting & Editing \\
\hline 2 & Closed-ended: 82 teachers & 73 & 71 & 68 \\
\hline 3 & Open-ended: 25 teachers & 22 & 6 & 15 \\
\hline 4 & Interviews: 9 teachers & 65 & 48 & 33 \\
\hline 5 & Open-ended: 2 facilitators & 38 & 13 & 25 \\
\hline
\end{tabular}

As seen in Table 7, data set 1 (systemic results) showed learners' writing pass rate was, on average, $20.1 \%$. Data set 2 revealed that teachers' quantitative rating of their implementation of the planning phase of the CAPS shared writing process was, on average, $73 \%$, that their rating of their implementation of the drafting phase was $71 \%$, and that their rating of their implementation of the editing phase was $68 \%$ (Table 7). The qualitative data consisted of three data sets, yielding the following findings:

- According to data set 3 (Table 7), encompassing the 25 teachers, an average of $22 \%$ of the CAPS requirements for the planning phase of shared writing were met, an average of six percent of the requirements for the drafting phase were met, and an average of $15 \%$ of the requirements for the editing phase were met (Table 7).

- The interviews (data set 4), where nine teachers had the opportunity to elaborate on their written descriptions of their CAPS implementation, yielded higher percentages of implementation: $65 \%$ for planning, $48 \%$ for drafting and $33 \%$ for editing (Table 7).

- The two facilitators (data set 5: open-ended questions) considered the rate of implementation of the CAPS planning phase to be $38 \%$, the rate of implementation of the drafting phase to be $13 \%$, and the rate of implementation of the editing phase to be $25 \%$ (Table 7).

A pattern was established between the quantitative and quantitative data sets. Compared with data sets 3, 4 and 5, data set 2 showed a noteworthy difference between the quantitative and qualitative data. Teachers rated their modelling (shared writing) of planning at $73 \%$ in the quantitative survey, but their described implementation of the CAPS requirements varied between $22 \%$ and $65 \%$. In terms of drafting, teachers rated their implementation at $71 \%$, while their descriptions varied between six percent and $48 \%$. Similarly, teachers considered their implementation of editing to be $68 \%$, while their description of their implementation varied between $15 \%$ and $33 \%$ (Table 7). Figure 3 (numbers 1-5 refer to the data sets) depicts a clear difference in how IP Afrikaans HL teachers quantitatively (data sets 1 and 2) rated their practices of shared writing compared to how they described (data sets 3 and 4) these practices. 
The purpose of the analysis was to explore the implementation of shared writing as a possible contributing factor to Grade 6 learners' poor performances in writing tests.

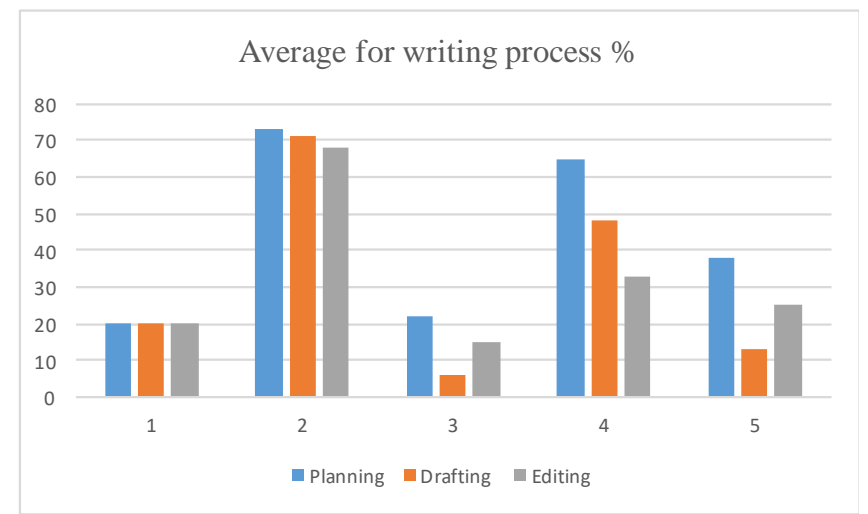

Figure 3: Average percentage of CAPS shared writing implementation

\section{FINDINGS AND INTERPRETATION}

The aim of this research was to determine whether and how West Coast District IP Afrikaans HL teachers implement the writing process using the shared writing method outlined in the IP Afrikaans HL CAPS, from the teachers' own point of view. Data set 2 was used to determine 'whether' teachers implement the CAPS writing process using shared writing. Data sets 3, 4 and 5, on the other hand, were used to determine and describe 'how' they implement shared writing. The quantitative and qualitative findings are now compared and discussed (Figure 3). In order to make a fair comparison of the quantitative and qualitative data on teachers' implementation of the writing process and shared writing, all data are presented as percentages. Gender, qualifications, exposure to READ training and teaching experience (data set 2) did not have a noteworthy influence on the findings.

1. There was a correlation among data sets 2, 3, 4 and 5 with regard to the writing process. One conclusion might be that teachers know and implement the five phases of the writing process, as reflected in the data. However, the results of data sets 2, 3, 4 and 5 contrast sharply with the Grade 6 Home Language results provided by data set 1 (Table 1). The evidence shows that teachers instruct the writing process, but the effectiveness of their instruction remains questionable. The question therefore becomes, 'Do teachers model the writing process using shared writing?' (South Africa, 2011: 13).

2. Data sets 3, 4 and 5 indicate that CAPS shared writing (Table 3) is not fully implemented. Considering the literacy systemic results and the qualitative data sets, one could question the in-depth knowledge that teachers have of shared writing. In particular, the quantitative findings (data set 2) show that teachers do not use shared writing as a scaffolding method to teach the writing process in IP Afrikaans HL classrooms in the West Coast District.

3. Data set 2 (82 participants) shows a gradual drop in percentages from the implementation of the writing process to the modelling of the planning, drafting and editing phases of the writing process. Data sets 3 (25 teachers), 4 (nine interviews) and 5 (two facilitators) show the same pattern: the highest percentages are for the writing process, with the percentages for the modelling of the writing process lower. Although the scores were higher during the interviews, the pattern in the qualitative data is the same. In terms of the shared writing scaffolding method outlined in CAPS, it might be the case that teachers themselves are not sure what is meant by modelling the planning, drafting and editing phases (Figure 3). One 
can assume that shared writing is not used effectively to teach the writing process. This lack of implementation is worrying: teachers cannot expect learners to develop an understanding of writing without first seeing their teacher's example, since there are many complex skills involved.

4. The last qualitative instrument was the observations of the two facilitators, who had a supportive approach towards teachers. Their view also concurs with the low implementation of the shared writing method, although they indicated that the teachers were willing to learn.

This last finding in particular indicates that the problem could lie somewhere other than with the teachers themselves. However, qualitative data show that teachers do not fully apply the shared writing methodology as described in CAPS as scaffolding. Following the implementation of shared writing over a period of three years, the impact of shared writing on the Grade 6 systemic results for literacy in the District could be assessed again, to determine whether shared writing is in fact a determining factor.

\section{CONCLUSION}

As mentioned, most learners in the WCED - and, more specifically, in the West Coast Education District, which was the focus of this study - are performing poorly in writing. Two possible explanations for the poor results were identified, with an emphasis on the CAPS requirements for the instruction of the writing process. First, this study aimed to determine whether the phases of the writing process (planning, drafting, editing, presenting) are implemented in IP Afrikaans HL classrooms. The findings of the study confirm that the phases of the writing process are indeed implemented. Second, the researcher investigated whether the shared writing method of writing instruction (i.e., modelling writing to the whole class and involving learners) is implemented in the West Coast Education District. Data sets 3, 4 and 5 reveal that CAPS shared writing (Table 3) is not fully implemented. The identified shortcomings in the educational system include a lack of training in scaffolding via the shared writing method. The WCED's Literacy Strategy has emphasised that 'there is general consensus that high-quality learning can be facilitated through "appropriate" teaching approaches' (South Africa, 2015: 9). In-depth training, demonstration of mastery and monitoring are all necessary to ensure that writing is taught effectively, and in a way that meets the requirements of the instructional methodology described by CAPS. The end result should be more competent Grade 6 writers, which could have a positive impact on the WCED annual systemic testing for literacy.

'The mediocre teacher tells. The good teacher explains. The superior teacher demonstrates.' William Arthur Ward.

\section{REFERENCES}

BARRINGER, M, C POHLMAN \& M ROBINSON. 2010. Schools for all kinds of minds. San Francisco, CA: Jossey-Bass.

BASIT, T. 2010. Conducting research in educational contexts. London: Continuum.

BEZUIDENHOUT, R \& J CRONJE. 2014. Quantitative data collection. In F du Plooy-Cilliers, C Davis \& R Bezuidenhout (Eds), Research matters. Cape Town: Juta. 228-250.

BOWER, V. 2011. Creative ways to teach literacy: Ideas for children ages 3 to 11. London: Sage. 
BRANDT, R. 1998. Powerful learning. Available from http://www.ascd.org/publications/books/198179.aspx [Accessed: 4 June 2016].

BUTTON, SB, JE MATHIEU \& DM ZAJAC. 1996. Goal orientation in organizational research: A conceptual and empirical foundation. Organizational Behaviour \& Human Decision Processes, 67(1):26-48.

CRESWELL, JW. 2008. Educational research: Planning, conducting and evaluating quantitative and qualitative research. 3rd ed. Upper Saddle River, NJ: Pearson.

CRESWELL, JW. 2009. Research design: Qualitative, quantitative and mixed methods approaches. 3rd ed. Thousand Oaks, CA: Sage.

CRESWELL, JW \& VL CLARK. 2011. Designing and conducting mixed methods research. Thousand Oaks, CA: Sage.

DAVIS, C. 2014. The research rationale. In F du Plooy-Cilliers, C Davis \& R Bezuidenhout (Eds). Research Matters. Claremont: Juta. 92-99.

DOUBLEDAY, AF, B BROWN, PA PATSTON, P JURGENS-TOEPKE, MD STROTMAN, A KOERBER, C HALEY, C BRIGGS \& GW KNIGHT. 2015. Social constructivism and case-writing for an integrated curriculum. Interdisciplinary Journal of Problem-Based Learning, 9(1). Available from http://docs.lib.purdue.edu/ijpbl [Accessed: 21 May 2016].

DRISCOLL, DL, A APPIAH-YEBOAH \& JR DOUGLAS. 2007. Merging qualitative and quantitative data in mixed methods research: How to and why not. Ecological and Environmental Anthropology, 3(1):28. Available from http://digitalcommons.unl.edu/cgi/view [Accessed: 16 April 2016].

DU PLOOY-CILLIERS, F \& J CRONJE. 2014. Quantitative data collection. In F du PlooyCilliers, C Davis \& R Bezuidenhout (Eds), Research matters. Cape Town: Juta. 147-172. EGGLETON, JE. 2010. Lighting the literacy fire. Cape Town: Bevan Printing.

FISCHER, R. 2002. Shared thinking: Metacognitive modelling in the literacy hour. Literacy, 36(2):63-67.

FINK, A. 2002. How to design survey studies. 2nd ed. Los Angeles, CA: Sage.

FRANKEL, JR \& NE WALLEN. 2006. How to design and evaluate research in education. 6th ed. Boston, MA: McGraw-Hill.

GAGNE, RM. 1970. The conditions of learning. 2nd ed. London: Holt, Reinhart and Winston.

GALBRAITH, D, S FORD, G WALKER \& J FORD. 2005. The contribution of different components of working memory to knowledge transformation during writing. Education Psychology, 2(1):113-145.

GALBRAITH, D. 2009. Cognitive models of writing. German as Foreign Language Journal, 2(3):1-22.

JICK, TD. 1979. Mixing qualitative and quantitative methods: Triangulation in action. Administrative Science Quarterly, 24(4):602-611. Available from http://www.jstor.org/stable/2392366 [Accessed: 1 June 2016].

KHAN, R. 2014. Quantitative data analysis. In F du Plooy-Cilliers, C Davis \& R Bezuidenhout (Eds), Research matters. Cape Town: Juta. 204-227.

KOONIN, M. 2014. Validity and reliability. In F du Plooy-Cilliers, C Davis \& R Bezuidenhout (Eds), Research matters. Cape Town: Juta. 252-260.

LAN, Y, C HUNG \& H HSU. 2011. Effects of Guided writing strategies on students' writing attitudes based on media richness theory. The Turkish Online Journal of Educational Technology, 10(4): 148-163.

LAYCOCK, L. 1991. Shared reading, shared writing. London: Centre for Language in Primary Education.

LOUW, M. 2014. Ethics in research. In F du Plooy-Cilliers, C Davis \& R Bezuidenhout (Eds), Research matters. Cape Town: Juta. 262-273. 
MILIAN, M. 2005. Reformulation: A means of constructing knowledge in shared writing. Education Studies in Language and Literature, 5(3):335-351.

PEARSON, PD \& MC GALLAGHER. 1983. The instruction of reading comprehension. Contemporary Educational Psychology, 8(3):317-344.

PAQUETTE, K. 2007. Encouraging primary students' writing through children's literature. Early Childhood Education Journal, 35(2):155-165.

PIAGET, J. 1970. Science of education and the psychology of the child. New York: Orion.

SOUTH AFRICA. 2011. National Curriculum Statement, Curriculum and Assessment Policy Statement Grades 4-6 English Home Language. Pretoria: Government Printer.

SOUTH AFRICA. 2015. 2014 Grade 6 WCED Systemic Test Results. Cape Town: Western Cape Education Department.

SPAULL, N. 2013. South Africa's education crisis: The quality of education in South Africa 1994-2011. Johannesburg: Centre for Development and Enterprise.

TANN, S. 1991. Developing language in primary classroom. London: Cassell.

TE KETE IPURANGI. 2015. Approaches to teaching writing: Shared writing. Available from http://literacyonline.tki.org.nz/Literacy-Online/Planning-for-my-students-needs/EffectiveLiteracy-Practice-Years-1-4/Approaches-to-teaching-writing [Accessed: 6 November 2015].

VYGOTSKY, LS, 1978. Mind in society. London: Harvard University Press.

VAN DER VEER, R. 2007. Lev Vygotsky. Continuum library of educational thought, volume 10. London: Continuum.

WALL, H. 2008. Interactive writing beyond the Primary Grades. The Reading Teacher, 62(2):149-152.

\section{BIOGRAPHICAL NOTES}

Ms Maryna de Lange is an educationalist in the West Coast District, Western Cape. She has been working as a teacher in special education for 17 years, in primary school nine years and another nine years as Language subject adviser serving 108 schools. Her educational interests are language methodology and supporting novice teachers.

Dr Hanlie Dippenaar is a senior lecturer in the Department of English, Faculty of Education, CPUT, Wellington. She has been working in the field of language teaching for the past 30 years and holds a PhD from Northwest University. Her research interests are community engagement, service-learning and language teaching.

Prof Johan Anker teaches Afrikaans at CPUT. His research interests are the Afrikaans literature and methodology of teaching Afrikaans, including reading comprehension. He has published and delivered papers at international conferences about trauma in literature, magical realism, young adult literature and the development of reading comprehension. 